\title{
A pesquisa em teopoética no Brasil: pesquisadores e produção bibliográfica
}

\author{
The research on Theopoetics in Brazil: researches and publications
}

\begin{abstract}
Resumo
O campo de conhecimento cunhado de Teopoética, relativo às interfaces entre literatura e o âmbito geral das ciências que estudam a religião e as espiritualidades, produziu nas últimas três ou quatro décadas, no Brasil, grande número de eventos e publicações. Este trabalho apresenta uma "radiografia" da produção bibliográfica no campo da Teopoética, com foco em quatro aspectos: i) gênero, idade e filiação institucional dos pesquisadores; ii) sua formação acadêmica e titulação; iii) produção bibliográfica e principais pesquisadores; iv) modelos teóricos, obras literárias e autores mais lidos. O trabalho de pesquisa se desenvolveu a partir de uma lista de pouco mais de 100 pesquisadores, dois terços deles doutores, vindos em geral da Teologia e/ou das Letras, com produção bibliográfica próxima dos 600 títulos (artigos, livros, capítulos, anais de congressos) e quase 80 dissertações e teses na área. Os dados apontam para um crescimento exponencial do interesse pelo diálogo religião-literatura nos últimos anos.
\end{abstract}

Palavras-chave: teopoética; teologia; literatura; produção bibliográfica.

\begin{abstract}
The field of knowledge named Theopoetics, associated with the interfaces between literature and the general scope of the sciences that study religion and the spiritualties, has produced a large number of events and publications in the last three or four decades in Brazil. This paper presents radiography of bibliographic output within Theopoetics, focusing on four aspects: i) gender, age and institutional affiliation of the researchers; ii) their academic background and titling; iii) publications in the area and main investigators; iv) models of reading, most widely-read writers and poets. This research was developed from a list of over 100 researchers (two-thirds of whom were doctors, usually of Theology and / or Literature) whose bibliographic production was close to 600 titles (articles, books, book chapters, annals of congress) and nearly 80 dissertations and theses in the area. The data point to an exponential growth of interest in religion-literature dialogue in recent years.
\end{abstract}

Keywords: theopoetics; theology; literature; bibliographic output.

\footnotetext{
Artigo recebido em 27 de outubro de 2014 e aprovado em 10 de dezembro de 2014.

* Doutor e Mestre em Letras. Bacharel em Teologia. Professor Adjunto da Pontifícia Universidade Católica de Minas Gerais, Departamento de Ciências da Religião. País de origem: Brasil. E-mail: cantarela@pucminas.br
} 


\section{Introdução}

O diálogo entre literatura e teologia constituiu, há várias décadas, um novo campo de conhecimento cunhado de Teopoética, marcado em geral por variados modos de "leitura religiosa" do texto literário. Uma inversão de perspectiva, mais recente, de leitura literária das narrativas sagradas, e o emergir de questões metodológicas que tangem as relações entre religião e literatura colaboraram para que o tema caísse no rol de interesse também das ciências da religião.

Em linha de princípio, o namoro entre religião e literatura pode-se explicar com facilidade: Do ponto de vista dos estudos da religião, incluindo as teologias, pressupõe-se que o universo particular das tradições religiosas e das espiritualidades não se estabelece fora da linguagem; e que o fenômeno religioso pode ser mais bem compreendido quando situado no conjunto das outras manifestações culturais, incluindo as expressões do mundo da arte. Do outro polo, trata-se de afirmar o papel possível da literatura e da crítica literária de propiciar, ao lado do conhecimento teórico-científico oferecido pela teologia, pelas ciências da religião e pelas ciências sociais, certa interpretação do fato religioso.

$\mathrm{Na}$ prática, a questão apresenta-se bem mais complexa. $\mathrm{O}$ interesse pela literatura em suas interfaces com a religião organizou, nos últimos trinta anos, dentro e fora do Brasil, numerosos eventos acadêmicos e produziu grande número de publicações. Coloca-se, dentre outros desafios relacionados a esse interesse, aquele de estabelecer critérios para a validação acadêmica de tão grande produção.

A pesquisa, cujos resultados parciais se apresentam neste texto, propôs-se a mapear a produção bibliográfica de caráter acadêmico no campo da Teopoética, no Brasil, e identificar categorias interpretativas (modelos de leitura) que subjazem a essas leituras. Apresentamos, por ora, apenas o mapa mais geral da pesquisa em Teopoética no Brasil, com foco em quatro aspectos principais: 1) Quem são os pesquisadores, relativamente às variáveis gênero, idade e filiação institucional 
distribuída por região; 2) Formação acadêmica dos pesquisadores e titulação, relacionadas às variáveis área de conhecimento e data de titulação; 3) Produção bibliográfica, por tipo (artigo, livro etc), em relação à variável tempo, e principais pesquisadores, sob o critério de volume de produção; 4) Esboço de modelos teóricos que subjazem às leituras, obras literárias e autores mais lidos.

O trabalho de pesquisa se fez, em linhas gerais, obedecendo aos seguintes passos: a) A partir de uma primeira lista de pesquisadores, de nosso conhecimento, foram buscados outros nomes: em publicações na área, na plataforma Lattes, em fascículos temáticos de periódicos eletrônicos, em anais de congressos e colóquios sobre o tema, nos sites de periódicos ou de associações que lidam com o tema ou que têm grupos de trabalho permanentes sobre o tema (Teoliterária, Alalite. Anpoll, Abralic, dentre outros). b) Busca, na plataforma Lattes, do curriculum vitae dos pesquisadores (cerca de 120, em lista provisória, reduzida ao total de 103, depois de leitura mais meticulosa). c) Quantificação e classificação da produção bibliográfica desses pesquisadores. d) Leitura de resumos, artigos, publicações em anais de congressos, capítulos de livros e alguns livros em vista da construção de uma primeira tipologia de leitura.

Cada seção do artigo se constitui de alguns gráficos com dados relativos à lista de 103 pesquisadores em Teopoética no Brasil. Os dados e os respectivos gráficos se fazem acompanhar por comentários, ora apenas traduzindo a informação geral que o gráfico ilustra, ora destacando algum aspecto ou detalhe considerado de importância ou que, no processo da pesquisa, trouxe interrogações e estranhamento.

Enquanto "radiografia” genérica, os dados obtidos na pesquisa necessitam certamente de análise mais aprofundada, particularmente em relação aos "modelos de leitura”, a fim de suscitar discussões de interesse às áreas de Teologia e de Ciências da Religião - empreendimento ao qual se dará continuidade. ${ }^{1}$

\footnotetext{
${ }^{1}$ O levantamento dos dados desta pesquisa se realizou durante o ano de 2013 com financiamento do Fundo de Investimento à Pesquisa (FIP) da PUC Minas. A pesquisa terá continuidade em 2015 com financiamento do CNPQ.
} 
As referências apresentadas ao final, mais que indicar de forma completa algumas fontes citadas no corpo do texto, destacam obras que trazem discussões teóricas e de caráter metodológico de interesse para a pesquisa.

\section{Identificação dos pesquisadores por gênero, idade e filiação institucional}

Uma das primeiras questões a que a pesquisa procurou responder, em relação aos pesquisadores, relacionava-se à variável "gênero": qual a proporção de homens e mulheres que pesquisam na área? (Ver gráfico 1, abaixo).

\section{Gráfico 1: Distribuição dos pesquisadores por gênero}

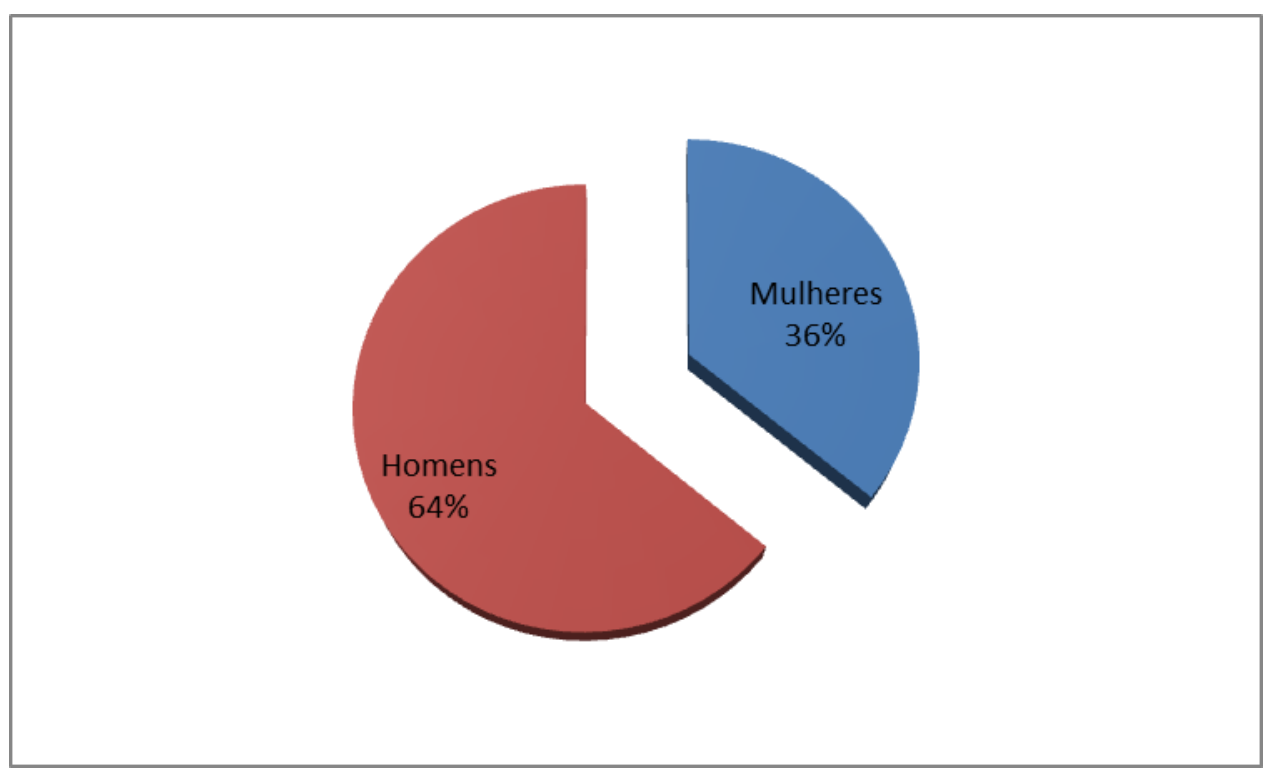

Fonte: Dados da pesquisa

A pergunta relacionou-se à percepção de que os cursos de graduação em Letras, seguindo a tendência das licenciaturas em geral, apresentam-se mais povoados de mulheres. Sendo Letras uma das áreas que conformam o campo da Teopoética, era de se esperar um número maior de mulheres entre os pesquisadores. Entretanto, os dados apontaram maior número de homens (66 homens versus 37 mulheres). Outros aspectos ajudarão a justificar os dados: a 
presença dos homens nos programas de pós-graduação de Letras, em maior volume que na graduação, assim como sua formação em Teologia, a outra área que configura o campo da Teopoética, onde sua presença mostra-se bem maior que a de mulheres. (Sobre a formação acadêmica dos pesquisadores, voltaremos adiante).

Para a estimativa da idade dos pesquisadores, tomamos como referência (na plataforma Lattes) o ano em que cada pesquisador iniciou sua graduação, quando teria então em torno de 19 ou 20 anos. Com base nisso, foi construída a pirâmide etária representada pelo gráfico 2, abaixo.

\section{Gráfico 2: Pirâmide etária dos pesquisadores}

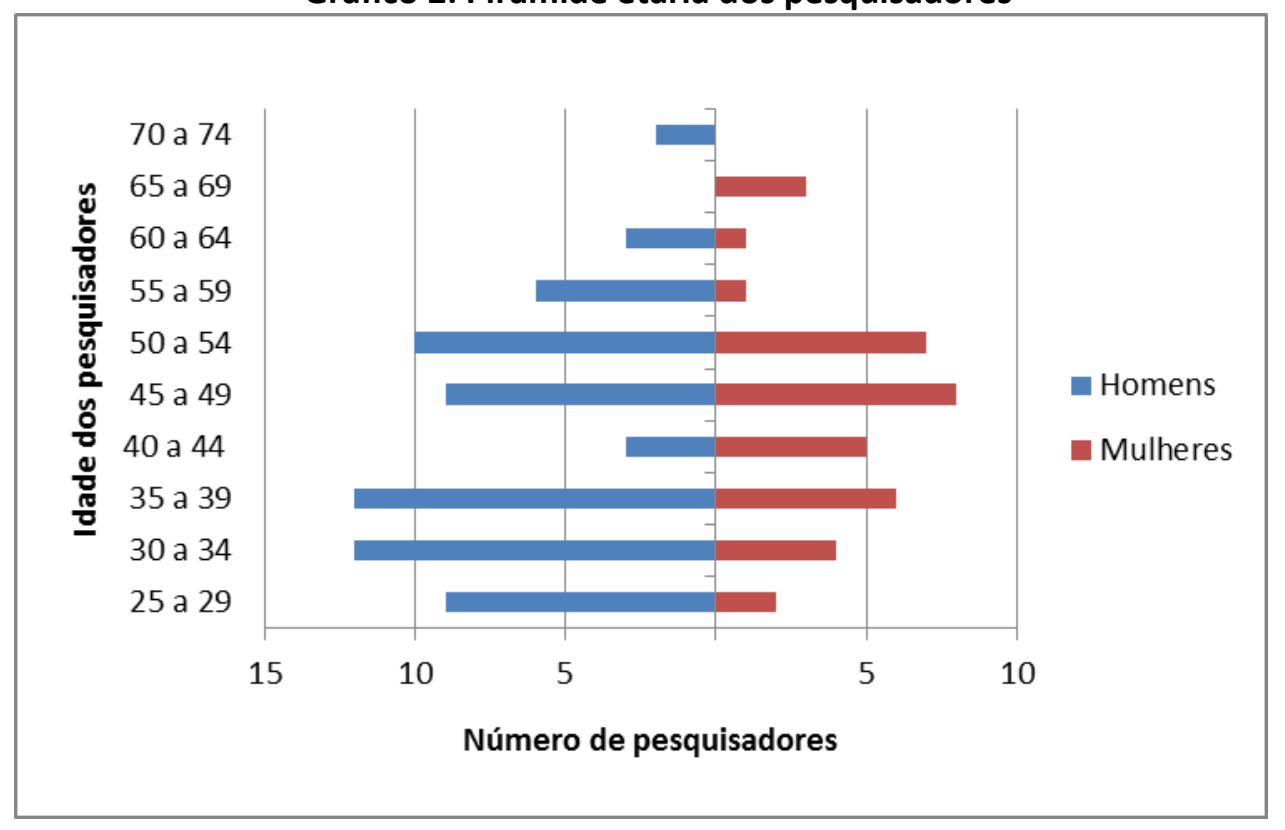

Fonte: Dados da pesquisa

Observa-se que pouco mais de um terço dos pesquisadores (34 deles) colocase na faixa dos 30 aos 39 anos de idade. Outro terço (também somando 34 pesquisadores) situa-se na faixa dos 45 aos 54 anos de idade. Talvez seja possível ver nessas duas faixas, respectivamente, um grande grupo de jovens pesquisadores e um grande grupo de pesquisadores academicamente mais maduros. Os dados, particularmente se relacionados à linha de tempo de titulação dos pesquisadores (gráfico 6, mais adiante), sugerem a vitalidade da pesquisa em Teopoética. 
A categoria "filiação institucional” refere-se à instituição, não necessariamente acadêmica, em que o pesquisador desenvolve seu trabalho como professor, pesquisador ou de outra forma. Consideramos dois tipos de instituição: públicas e confessionais. A coluna “outras” (do gráfico 3, abaixo) abrange instituições particulares não confessionais, não necessariamente acadêmicas, e certo número de pesquisadores cuja filiação institucional não pôde ser identificada.

Gráfico 3: Tipo de instituição a que se filiam os pesquisadores

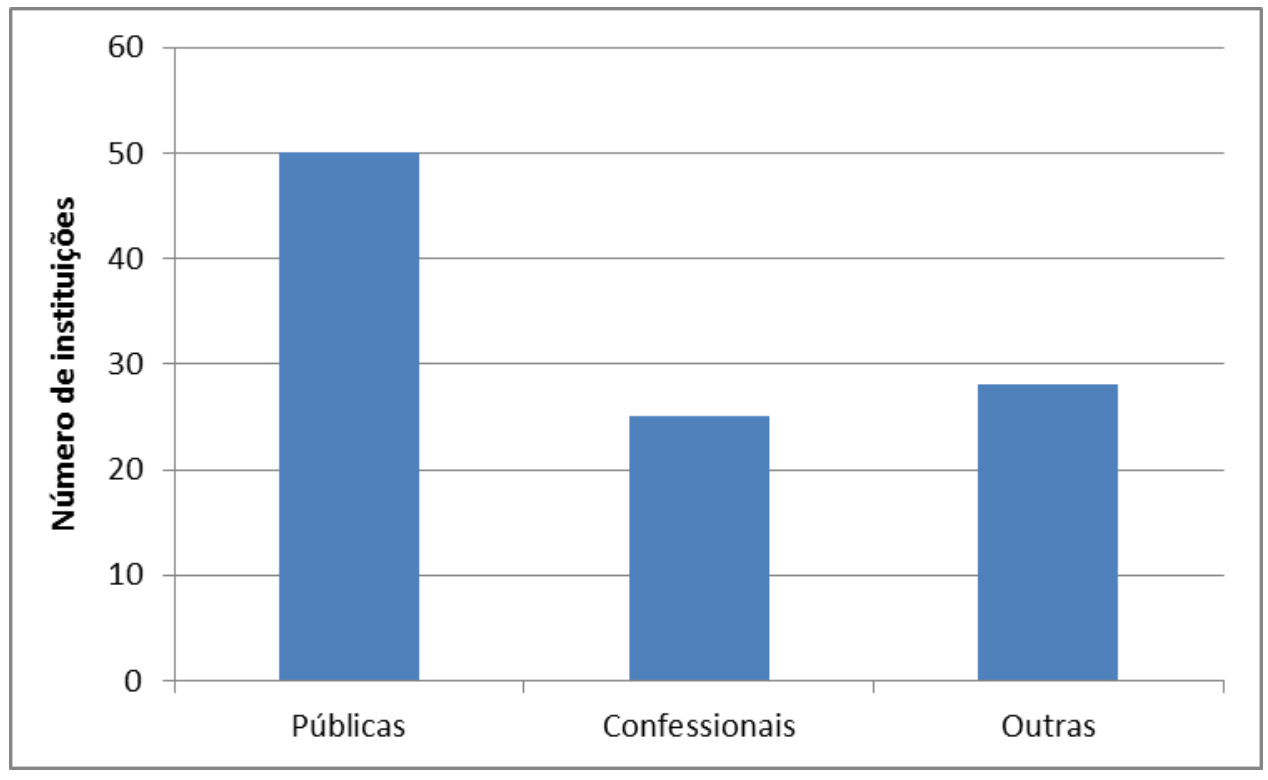

Fonte: Dados da pesquisa

Considerando o interesse por aspectos relativos ao campo da religião presentes nas obras literárias - traço fundante da Teopoética -, levantamos a hipótese de que tal interesse estaria representado com maior frequência em universidades e faculdades confessionais (católicas, evangélicas e outras). Isso não se mostrou verdadeiro, conforme se pode verificar pelos dados expressos no gráfico 3, acima. Os pesquisadores lotados em instituições públicas somam praticamente o dobro dos que estão em instituições confessionais. 
A relativa ausência do interesse pela Teopoética em instituições confessionais talvez possa ser explicado pelo fato de esse conhecimento representar uma interlocução mais livre de dogmatismos teológicos ou científicos para a construção do discurso sobre a religião - conforme expresso por Magalhães (2009, p. 25). Tal liberdade na abordagem do fato religioso pode não ser bem vinda, para muitas instituições religiosas.

Em relação à distribuição territorial das instituições a que se vinculam os pesquisadores em Teopoética (gráfico 4, abaixo), observa-se que, acompanhando o quadro brasileiro, a maior parte dos pesquisadores trabalha em instituições localizadas no sudeste, seguindo-se a região sul. No sudeste estão concentradas cerca de 50 dessas instituições, contra apenas 2 na região centro-oeste.

No sudeste encontram-se a metade das instituições públicas e a quase totalidade (22 em 25) das instituições confessionais que abrigam pesquisadores em Teopoética. Nas regiões sudeste e sul juntas encontram-se 70\% das instituições públicas nas quais encontramos pesquisadores na área.

\section{Gráfico 4: Filiação institucional por região}

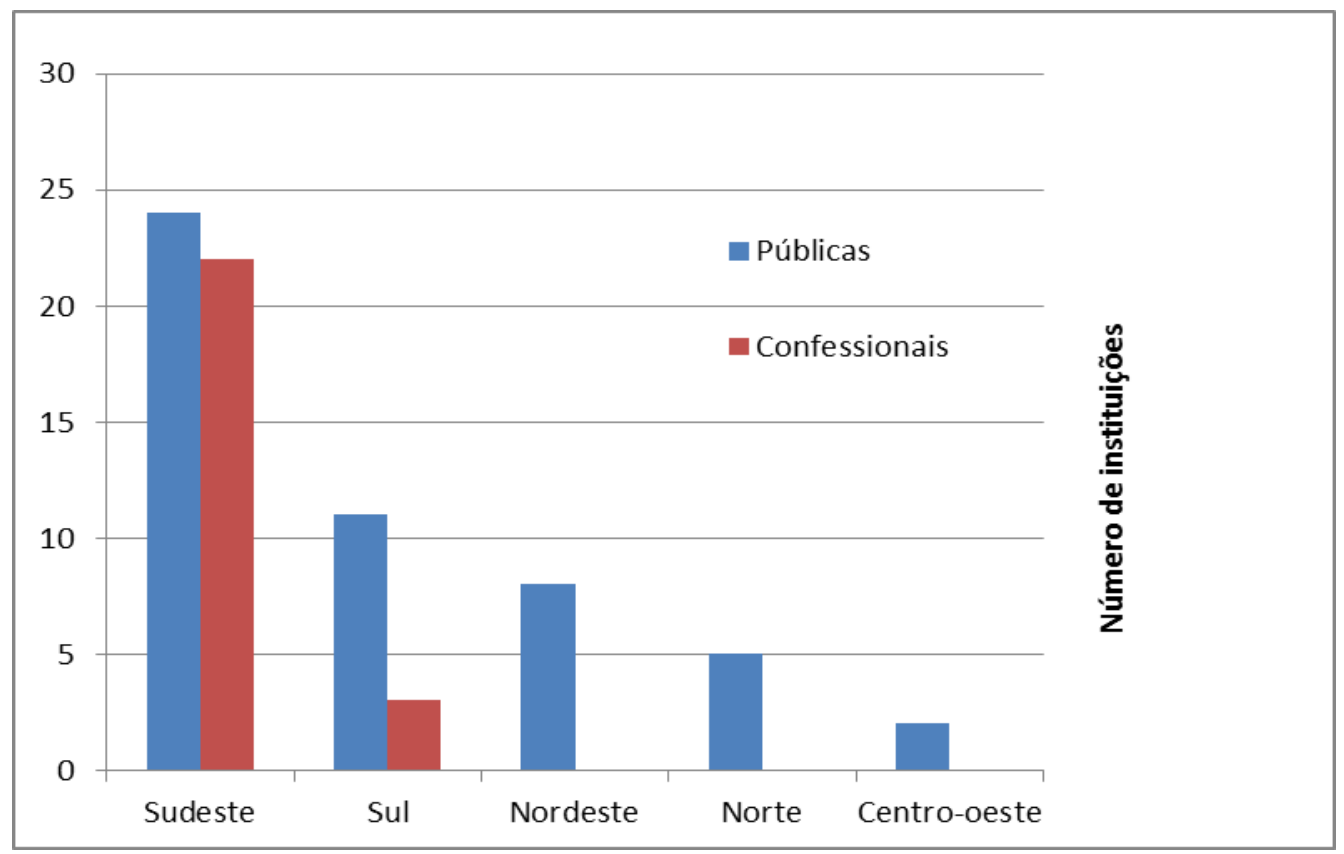

Fonte: Dados da pesquisa 


\section{Formação acadêmica e titulação dos pesquisadores}

Em relação à titulação máxima dos pesquisadores, foram considerados os títulos efetivamente já obtidos. Assim, o pesquisador que estivesse fazendo seu doutoramento, ainda que em fase adiantada, foi identificado no grau "mestre". Não foram considerados os títulos que não conferem grau (especialista, pós-doutor). Sob o critério quantitativo da titulação, o campo de estudos da Teopoética apresenta-se com alto nível de preparação acadêmica. (Da produção acadêmica na área trataremos adiante). O gráfico abaixo ilustra a distribuição percentual da titulação máxima dos pesquisadores em Teopoética.

\section{Gráfico 5: Titulação máxima dos pesquisadores em Teopoética}

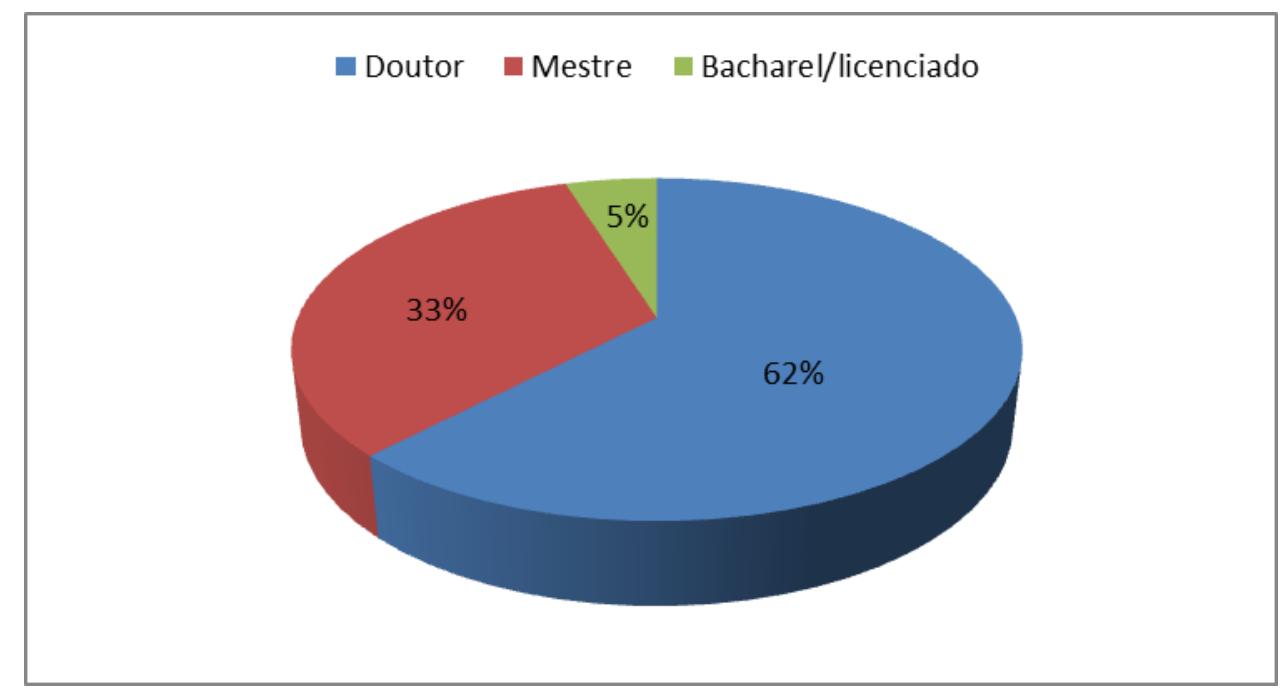

Fonte: Dados da pesquisa

Dos 103 pesquisadores registrados pela pesquisa, quase 2/3 (dois terços) têm o título de doutor. Um terço tem o grau de mestre. E apenas 5 pesquisadores situam-se no grau de bacharel/licenciado (destacando contudo que, desses cinco, três estão com o mestrado em andamento). (Gráfico 5). 
Observa-se também que o acesso à pós-graduação stricto sensu, da parte dos pesquisadores em Teopoética, é relativamente recente (gráfico 6, abaixo). Cerca de 2/3 dos pesquisadores que têm apenas o título de mestre (23 no total) o obtiveram entre 2009 e 2013. No caso dos que já tem o título de doutor, cerca de 1/5 dos títulos foi obtido antes do ano 2000. Mais de 50 títulos de doutor vieram depois do ano 2000, sendo que mais da metade desses (total de 28 títulos) foi obtida entre 2009 e 2013. Pode-se observar, pelas linhas do gráfico 6, abaixo, o crescimento vertiginoso da busca pela pós-graduação stricto sensu por parte dos pesquisadores em Teopoética. Esta linha de crescimento acompanha uma tendência geral de acesso aos mestrados e doutorados nos últimos anos, no Brasil.

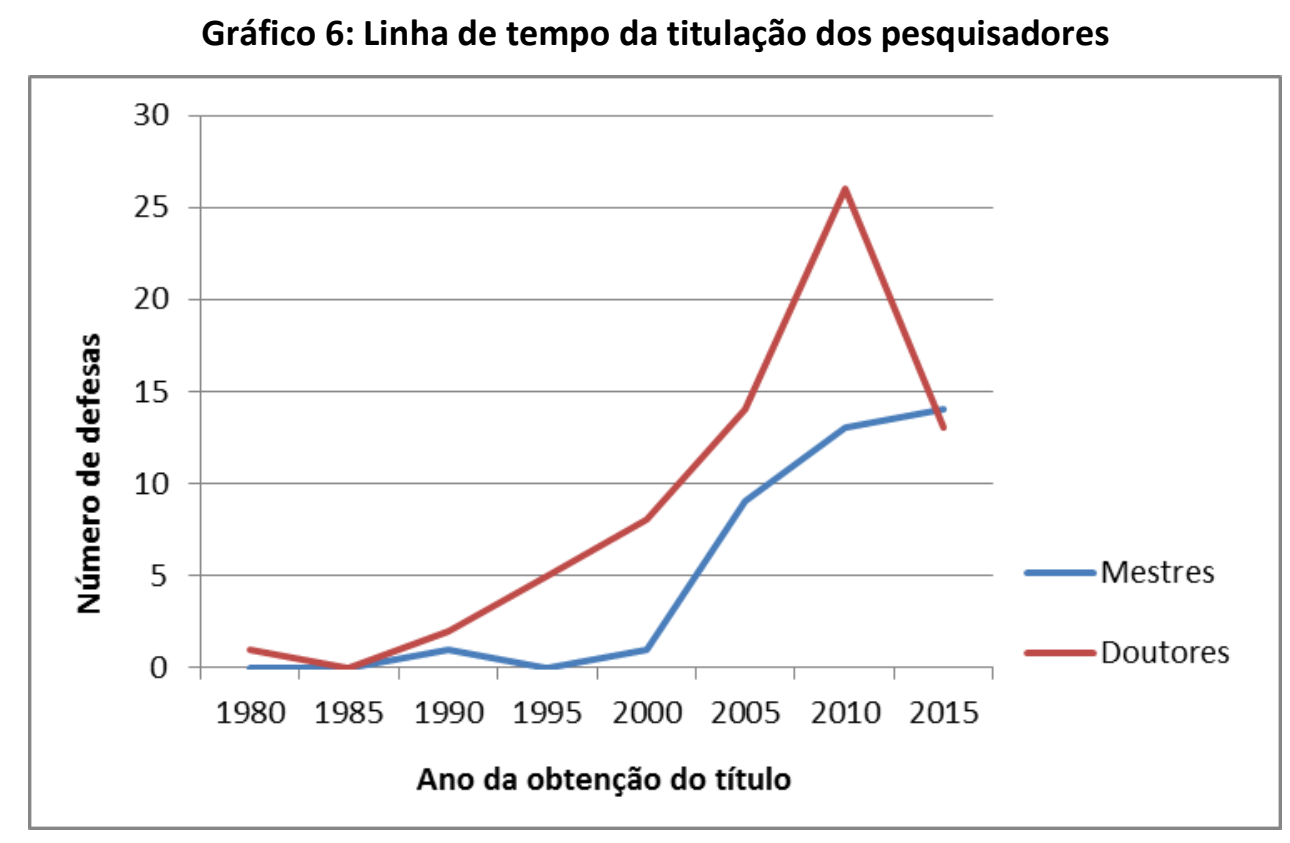

Fonte: Dados da pesquisa

O gráfico 7, abaixo, refere-se às áreas de conhecimento de onde provêm os pesquisadores em Teopoética. Observe-se que os dados do gráfico não são percentuais, mas indicam a concentração total de pesquisadores em cada área. Isto porque certo número de pesquisadores (certa de 1/4 do total) passou por mais de uma graduação, em geral pelos cursos de Filosofia e Teologia, fato relativamente comum na formação seminarística tanto no contexto católico como no evangélico. 
Em 7 casos, o pesquisador passa primeiro pela Teologia e depois por Letras. Da graduação ao doutorado, a maior concentração de pesquisadores se dá na área de Letras.

Gráfico 7: Áreas de conhecimento em que se concentram os pesquisadores

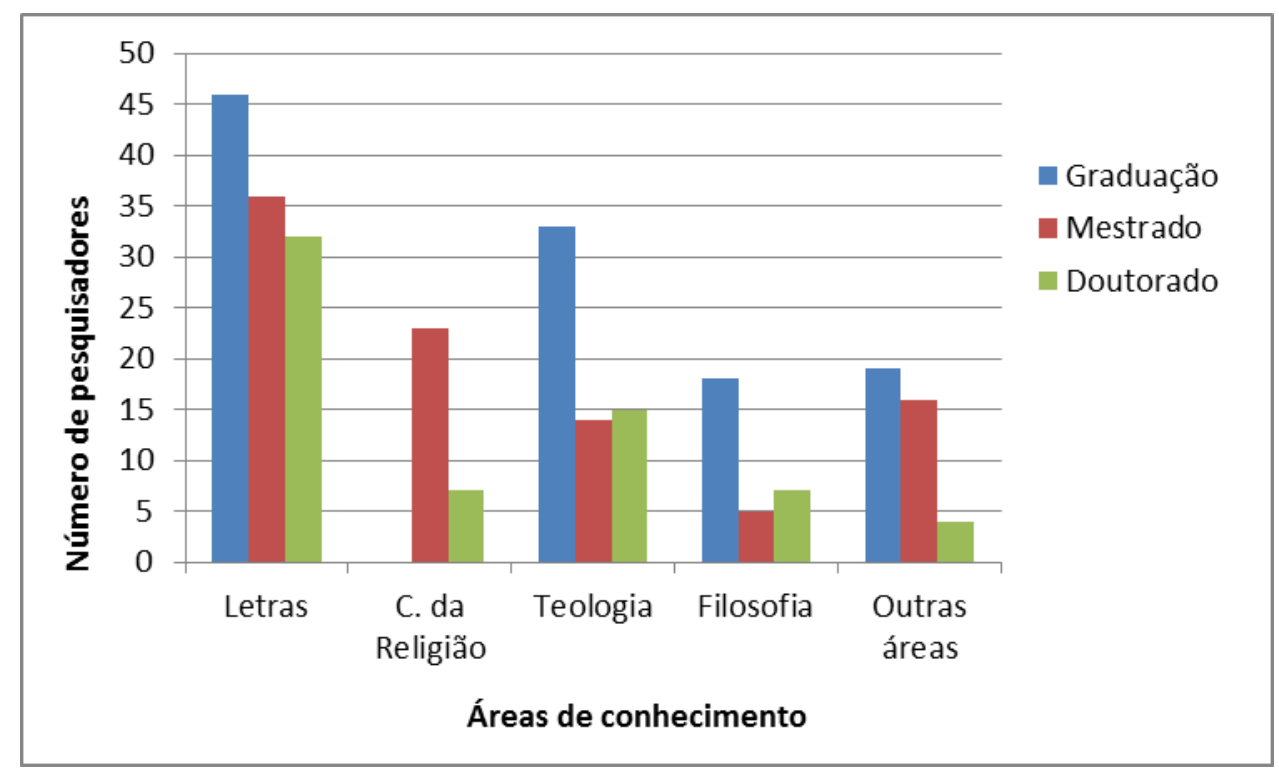

Fonte: Dados da pesquisa

Em relação à formação no nível da graduação (representada pela coluna azul), observa-se que não aparece a área de Ciências da Religião. Isto se pode explicar pela quase total ausência de cursos dessa área no nível da graduação. $\mathrm{Na}$ graduação, há um número relativamente grande de pesquisadores (quase 1/5 deles) que fizeram sua formação em outras áreas, algumas vezes como segunda graduação além da Teologia. Destaca-se a área de Comunicação Social (6 casos), seguida de Ciências Sociais (4 casos). Os demais se distribuem entre Psicologia, Serviço Social, História, Pedagogia e Educação Artística, com um ou dois pesquisadores por área.

No nível do mestrado (coluna vermelha), a área de maior concentração de pesquisadores continua a ser a de Letras. Observe-se, no entanto, que a soma dos pesquisadores que fizeram mestrado em Ciências a Religião com os que fizeram 
Teologia ultrapassa o montante de Letras. Vale observar também que os mestres em Ciências da Religião (23) ultrapassam em mais de 30\% o número de mestres em Teologia (14)

Também no nível do doutorado (coluna verde), a área de Letras apresenta-se como aquela que concentra maior número de pesquisadores. Diferentemente do que aconteceu no mestrado, a área de Letras ultrapassa em cerca de 30\% as áreas de Ciências da Religião e Teologia juntas. Mais que isso: dos mais de 6o pesquisadores com título de doutor, cerca da metade (32 pesquisadores) o tem na área de Letras. Em contraposição ao mestrado, observa-se no nível do doutorado uma espécie de "retorno à Teologia”. As teses em Teologia (15) ultrapassam o dobro das teses em Ciências da Religião (7).

Vale completar esta seção sobre as áreas de formação acadêmica dos pesquisadores em Teopoética com um destaque: o "trânsito" entre as áreas. O “trânsito" entre a área de Letras, de um lado, e as de Ciências da Religião e Teologia juntas, de outro, mostra-se relativamente pouco frequente. Dos 103 pesquisadores listados pela pesquisa, 51 passaram pela área de Teologia ou de Ciências da Religião, em algum momento de sua formação (graduação, mestrado ou doutorado). Da mesma forma, do total dos pesquisadores, 53 passaram por Letras, em algum momento de sua formação acadêmica. Entretanto, apenas 15 pesquisadores daquele total transitaram pelas duas áreas. Curiosamente, 9 pesquisadores não passaram por Letras nem por nenhuma das duas áreas ligadas ao campo religioso. Esses dados indicam a relativa importância de buscar por outros métodos (entrevistas, história oral e outros) as possíveis razões do interesse dos pesquisadores pelas interfaces entre religião e literatura. 


\section{Produção bibliográfica e principais pesquisadores}

Os dados sobre a produção bibliográfica dos pesquisadores em Teopoética impressionam por seu volume. Em pouco mais de 10 anos, de 2000 a 2012 (descontando-se o período anterior a 2000, quando a produção mostra-se parca), os 103 pesquisadores listados ofereceram nada menos que 572 publicações, dentre livros, capítulos de livros, artigos e textos completos publicados em anais de eventos. Esses dados perfazem a média de 5,55 publicações por pesquisador.

Além desse volume de publicações, 57 dos pesquisadores escreveram 44 dissertações de mestrado e 36 teses de doutorado versando sobre temáticas que configuram o campo da Teopoética, conforme os critérios considerados no processo da pesquisa. Desses 57 pesquisadores, 22 dedicaram-se ao assunto no mestrado $e$ no doutorado. Isso amplia o cômputo para o total de 652 produções bibliográficas. (Os gráficos enumerados de 8 a 11, abaixo, destacam aspectos da produção bibliográfica dos pesquisadores em Teopoética).

Certamente, não se pode considerar cada uma dessas publicações bibliográficas como um produto singular e original. Com certa frequência (que não foi medida pela pesquisa), o pesquisador apresenta sua pesquisa de pós-graduação, ainda em andamento, no formato de comunicação, em algum congresso, fazendo originar daí uma publicação em anais de congresso. Seguem-se a escrita e a defesa da dissertação ou tese, da qual podem nascer posteriormente alguns artigos ou capítulos de livros. $\mathrm{Na}$ impossibilidade de mensurar tal dinâmica, e seguindo o sistema de registro da plataforma Lattes, a pesquisa optou por contabilizar cada produção bibliográfica, independentemente de duas ou três publicações de um mesmo autor versarem sobre um mesmo assunto, sob um mesmo foco. 
Gráfico 8: Distribuição da produção bibliográfica por autores

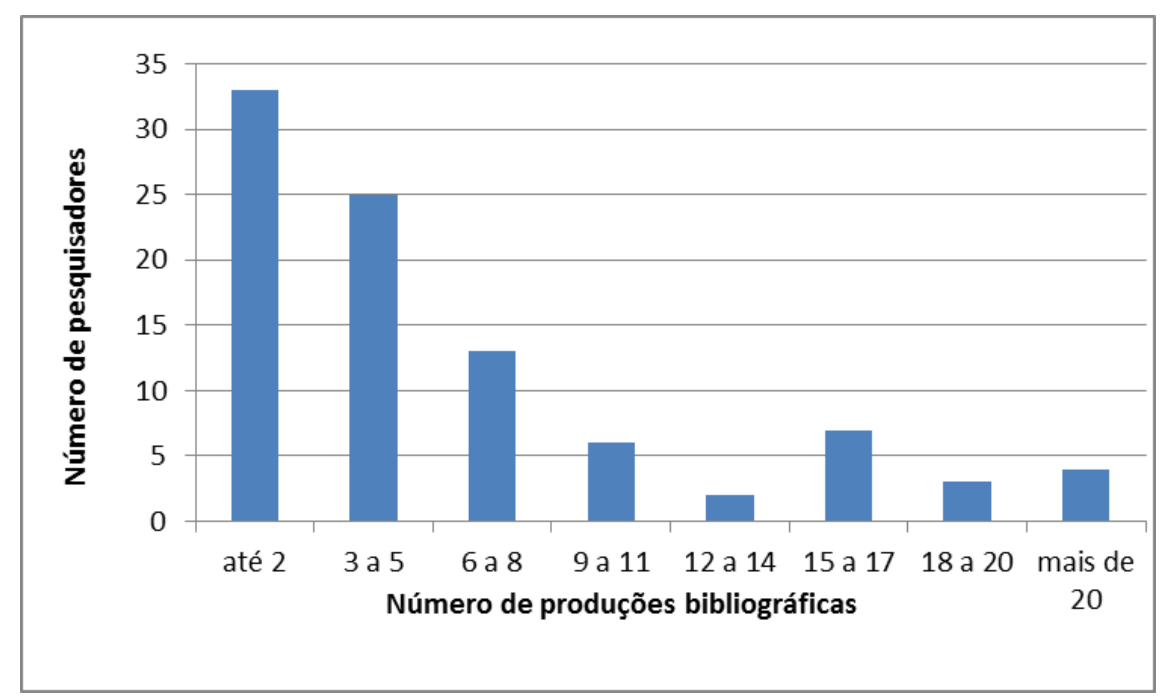

Fonte: Dados da pesquisa

Considerando-se a distribuição da produção bibliográfica pelo número de autores (gráfico 8, acima), pode-se dizer que a produção mostra-se restrita. Cerca de 1/3 dos pesquisadores não foi além de 2 produções bibliográficas. A quarta parte dos pesquisadores limitou-se a no máximo 5 produções. Assim, pouco mais de 70\% dos pesquisadores assinam 217 publicações (do total de 572). No outro extremo, um número reduzido de pesquisadores (21 do total) responsabilizou-se por nada menos que 355 produções bibliográficas.

Em relação ao tipo de produção bibliográfica, adotou-se, também aqui, o sistema de classificação da plataforma Lattes. O gráfico 9, abaixo, apresenta o número de produções bibliográficas conforme o tipo de publicação: artigo, livro, resumo completo em anais de congresso, dissertações e teses. 
Gráfico 9: Número de publicações conforme o tipo de produção bibliográfica

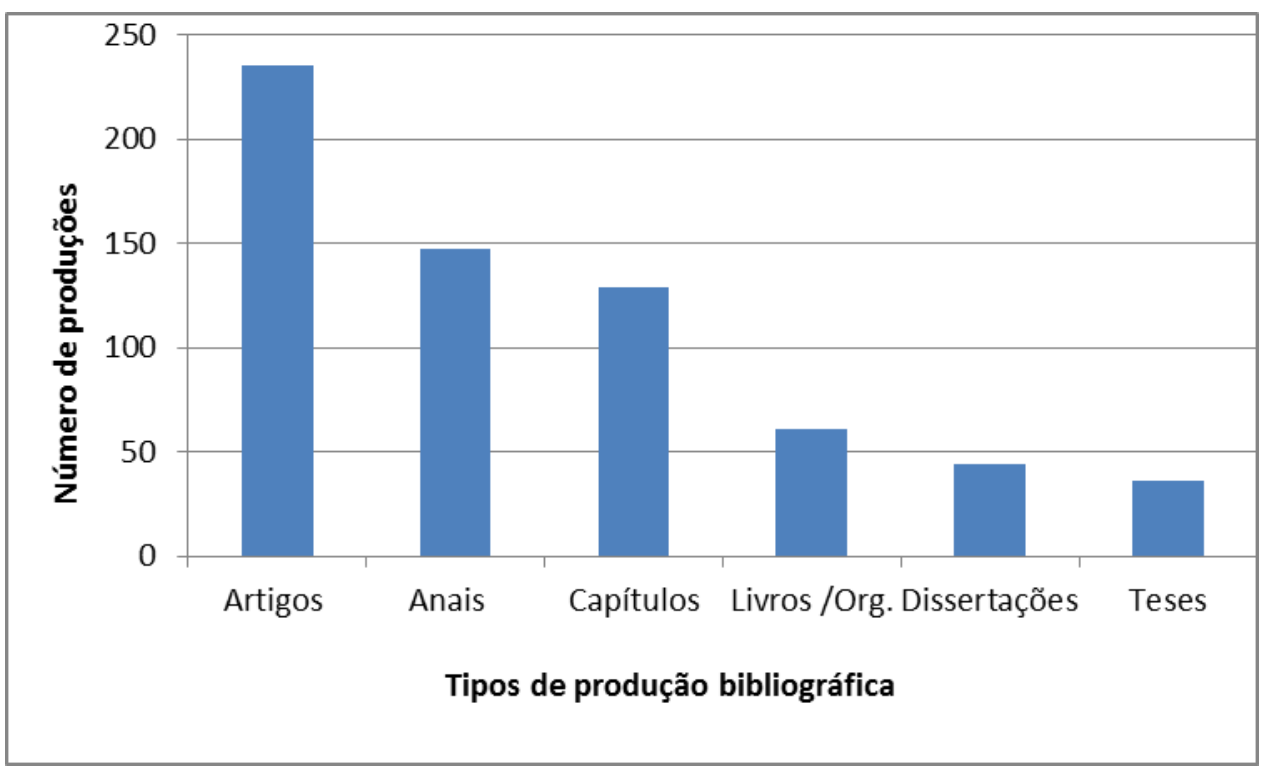

Fonte: Dados da pesquisa

A produção de livros por autor individual e enquanto organização de obra coletiva foi computada como um único tipo. O interesse era saber o número de títulos na área. Chegou-se ao registro de 66 títulos, publicados entre os anos 2000 e 2012.

Dentre os diversos tipos de produção bibliográfica, os artigos aparecem em maior quantidade (235 do total de 572), seguidos das publicações em anais de congresso (147), dos quais se aproximam numericamente os capítulos de livros (129). (Gráfico 9, acima).

O maior volume de artigos talvez possa ser explicado pelo interesse dos autores em receber algum tipo de pontuação pela sua produção. Observe-se que a estratificação da qualidade da produção intelectual é relativamente recente no Brasil. Entretanto, o Qualis Periódicos, que pontua a produção de artigos, funciona desde 2000, enquanto o Qualis Livros estabeleceu critérios classificatórios apenas em 2013. Vale observar ainda que a produção individual de um livro é relativamente mais complexa e demorada que a de um artigo. 
Afirmamos anteriormente que a produção bibliográfica dos pesquisadores em Teopoética impressiona por seu volume. Mais: acompanhando a tendência geral da educação superior no Brasil, o interesse pela pesquisa nessa área e sua correlata produção acadêmica revelam-se fenômenos relativamente recentes. A produção bibliográfica dos últimos quatro anos contemplados pela pesquisa (2009 a 2012) repete em volume a produção de uma década inteira (1999 a 2008). A linha que registra o crescimento da produção bibliográfica mostra-se, assim, em franca ascensão. O gráfico 10, abaixo, desenha a linha geral de crescimento da produção bibliográfica entre 1997 e 2012, distribuindo as publicações por tipo.

Gráfico 10: Distribuição das publicações por tipo de 1997 a 2012

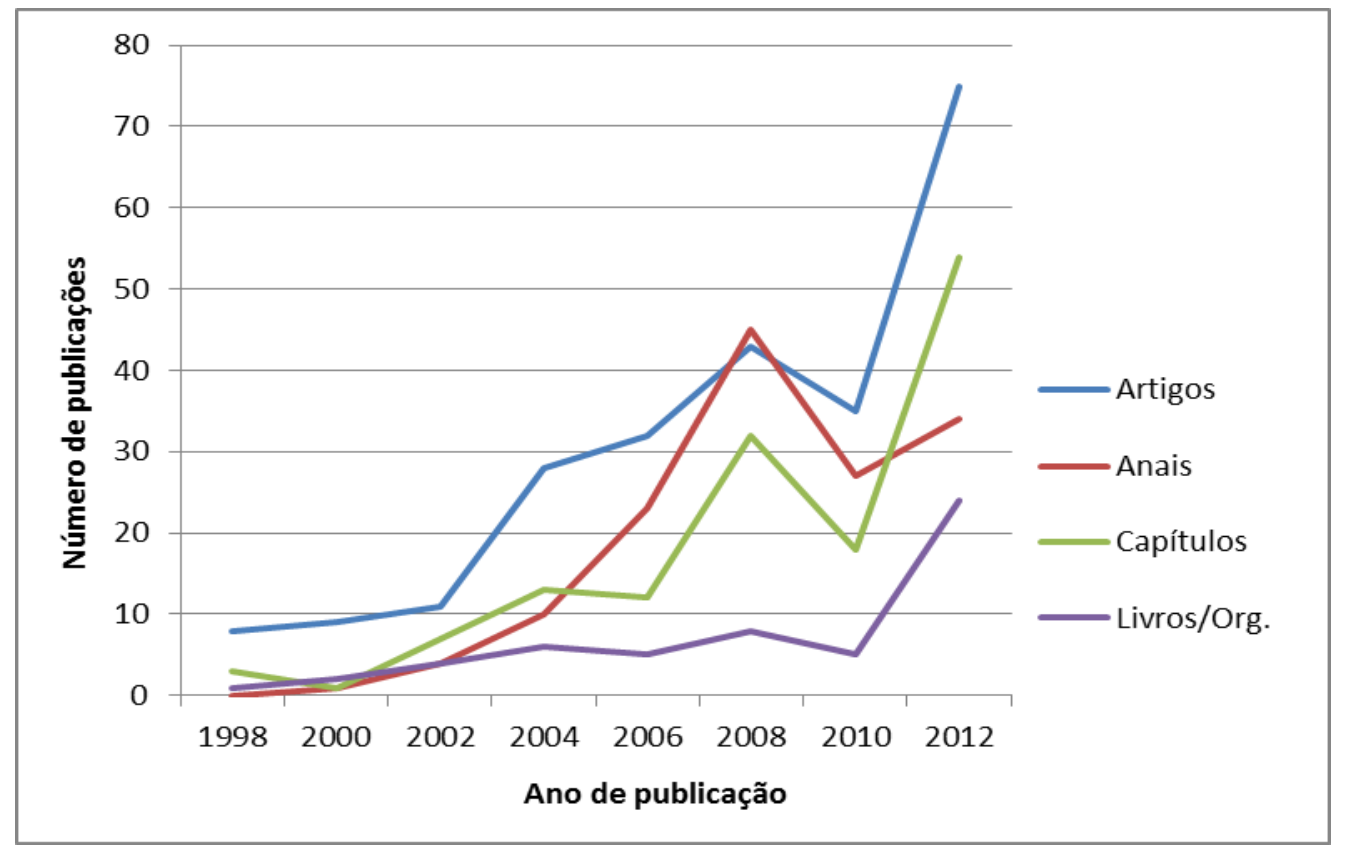

Fonte: Dados da pesquisa

Por alguma razão que a pesquisa não conseguiu detectar, nos anos de 2009 e 2010 registra-se uma grande queda na produção bibliográfica. Curiosamente, a diminuição das publicações se dá em todos os tipos de publicação (artigos, anais de congresso, capítulos de livros e livros). Levantou-se a hipótese de que não teriam sido organizados congressos e colóquios naqueles dois anos. Mas a hipótese não se confirmou. A queda da produção não se deveu a falta de eventos na área. Contra a 
tendência geral de queda de produção bibliográfica na área, naqueles dois anos, houve um aumento de defesas de dissertações e teses. (Gráfico 11, abaixo).

\section{Gráfico 11: Comparação entre o volume de teses/ dissertações e a produção bibliográfica}

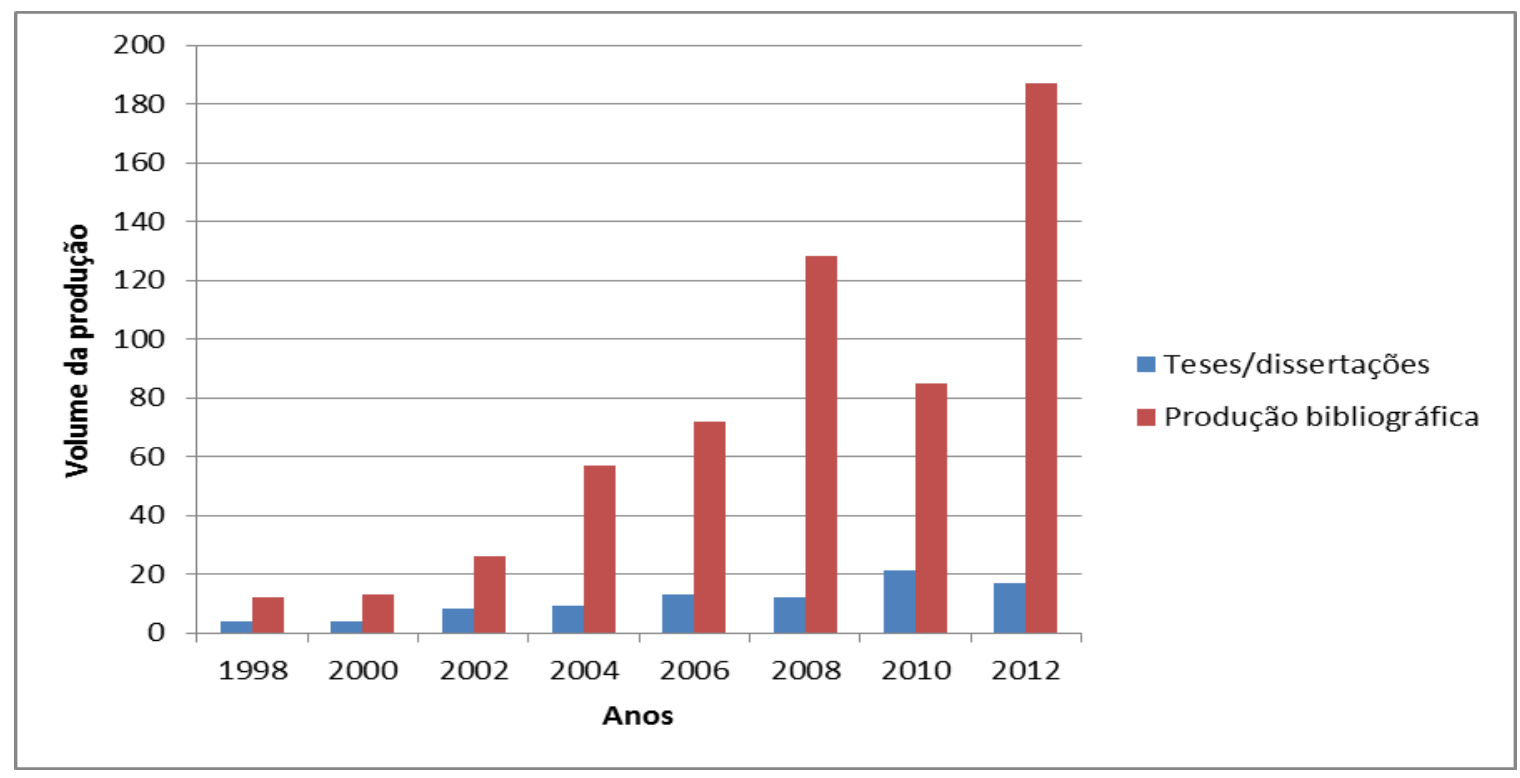

Fonte: Dados da pesquisa

Conforme se pode observar pelo gráfico, a distribuição da produção bibliográfica entre 1997 e 2012 cresceu muito, com a linha de crescimento alterada negativamente pela referida queda. Em contrapartida, os anos 2009 e 2010 mantiveram a dinâmica de aumento das teses e dissertações, cuja relativa diminuição ocorrerá nos anos de 2011 e 2012. Arrolamos a hipótese (sem confirmação por esta pesquisa) de que a diminuição de produção bibliográfica naqueles dois anos pode ter ocorrido justamente pelo volume de demandas correlacionadas aos processos de orientação e defesa das dissertações e teses.

Conforme foi salientado acima (relativamente ao gráfico 8), ao apresentar a correlação entre o número de pesquisadores e o volume de publicações, um número relativamente pequeno de pesquisadores (cerca de $1 / 5$ deles) foi responsável por quase 2/3 da produção bibliográfica na área de Teopoética. Sob o critério quantitativo da produção bibliográfica, procuramos identificar quem 
seriam os principais pesquisadores na área. Em vista de não permitir muitas ressalvas em relação ao critério adotado, estabelecemos o critério a partir de um nível relativamente elevado: produção bibliográfica igual ou acima de quinze publicações na área. Isso nos levou a uma lista de 14 pesquisadores, responsáveis por 274 produções bibliográficas na área. Em outras medidas: cerca de 15\% dos pesquisadores encarregaram-se de quase a metade da produção bibliográfica em Teopoética.

Sem desmerecer a importância ou a qualidade do trabalho de outros pesquisadores, sob os critérios acima descritos constituem a lista dos principais pesquisadores em Teopoética (em ordem alfabética organizada pelo sobrenome): José Carlos Barcelos, Eli Brandão, Carlos Caldas, Douglas Rodrigues da Conceição, Salma Ferraz, Eduardo Gross, João Leonel, Antonio Magalhães, Antonio Nery, Cleide Oliveira, Alessandro Rocha, Anaxsuell Silva, Suzi Sperber e Waldecy Tenório. Certamente, sob outros critérios, a lista poderá ser mudada ou ampliada.

Uma caracterização geral dos que compõem a lista dos 14 principais pesquisadores em Teopoética pode ser traduzida por estes números: São 11 homens e 3 mulheres. Exceto um, são doutores. Dentre os catorze, 9 têm dissertação ou tese na área. Desses nove, 5 têm dissertação $e$ tese em Teopoética. Nove passaram pela área de Letras em algum momento de sua formação, sendo que 4 deles passaram só por Letras. Oito passaram por Teologia ou Ciências da Religião em algum momento de sua formação, sendo que 3 deles passaram só por Teologia ou Ciências da Religião. Dos 14, nove estão em instituições públicas. Nove filiam-se a instituições do sudeste do Brasil. Os números indicam que, excetuando o traço de maior quantidade de publicações na área, a situação dos principais pesquisadores em Teopoética segue em linhas gerais o mapa do conjunto dos pesquisadores.

Ainda que sua produção seja diversa em relação a autores e temas, quase todos esses pesquisadores compartilham um traço em comum: o interesse em discutir e buscar sustentação teórica para o trabalho de estabelecer interfaces entre religião e literatura. Talvez esse traço pudesse ser adotado como critério, ainda que 
de operacionalização mais complexa, para identificar os pesquisadores em termos de relativa importância para a área, assim como avaliar a qualidade da produção bibliográfica.

Em relação aos principais pesquisadores, vale ainda destacar que também eles fizeram sua pós-graduação em época relativamente recente. Apenas 3 nomes da lista (Antonio Magalhães, Suzi Sperber e Waldecy Tenório) obtiveram seu doutoramento anteriormente a 1996. Chamou-nos a atenção o fato de alguns pesquisadores que, a despeito de não constarem da lista dos autores mais profícuos (aqueles que produziram 15 ou mais publicações na área), aparecem com grande frequência nas listas de referências de outros pesquisadores, sendo seus nomes reconhecidos como de grande importância para a área. Citam-se, dentre outros, Maria Clara Lucchetti Bingemer, Eliana Yunes e Antonio Manzatto. Este último, com sua tese de doutorado (1993) versando sobre o caráter antropológico da obra de Jorge Amado, costuma ser destacado como um dos primeiros a tratar sistematicamente a questão da Teopoética no Brasil.

\section{Modelos teóricos, obras literárias e autores mais lidos}

Um dos principais objetivos da pesquisa que subsidia este artigo formulouse, em sua fase projetiva, em termos de identificar categorias interpretativas ou modelos de leitura que subjazem à produção bibliográfica em Teopoética no Brasil. Se o levantamento da produção, por si, representou tarefa relativamente complexa, a busca por modelos de leitura revelou uma teia ainda mais intrincada de possibilidades. Apresentamos em seguida, em linhas muito gerais, duas rotas que, combinadas, podem ser de grande ajuda na busca por aqueles modelos de leitura: o estudo das discussões teóricas já existentes e a leitura crítica das obras literárias e dos autores mais lidos. 
Podemos encontrar, em maior ou menor escala, em inúmeras publicações em Teopoética, discussões teóricas e de caráter metodológico. Destacamos (e indicamos nas referências), dentre outras (em ordem alfabética): Barcelos, 2000; De Mori; Santos; Caldas, 2011; Cantarela, 2010; Conceição, 2010; Ferraz, 2012; Gross, 2012; Magalhães, 2009; Manzatto, 1994; Paula, 2011; Rocha; Yunes; Carvalho, 2011; Sperber, 2011; Villas Boas, 2013.

As discussões teóricas e metodológicas trazidas por essas obras revelam, já de começo, a riqueza de modos de construir interfaces entre religião/teologia e literatura. E indicam igualmente grande diversidade de princípios e fundamentos para o fazer teopoético. Dentre as diversas propostas, podem ser destacados dois caminhos mais representativos das discussões: i) aquele que estabelece, a um só tempo, correlação e contraste entre o fazer teológico e o fazer literário; ii) e o que segue um percurso histórico com as sucessivas tendências das relações entre teologia/ciências da religião e literatura.

O modelo da correlação/contraste entre o fazer teológico e o fazer literário foca, em geral, as conexões possíveis entre o literário e o teológico. Parte do pressuposto de que há uma imprecisão de limites entre o discurso literário, objeto da fruição estética e da crítica literária, e o discurso religioso, objeto da fruição religiosa e da teologia. O texto literário não se oferece como objeto de leitura apenas à crítica literária, assim como o texto de caráter religioso não se reduz a mero objeto de estudo da teologia. Assim, por exemplo, antes de ser interpretado como palavra de Deus, o texto bíblico se entende como mito, saga, lenda, canto. E, nesse sentido, pode interessar ao leitor de literatura. Da mesma forma, a literatura, ao "redescrever" o mundo com seu poder heurístico, se oferece como fértil terreno para a teologia.

O modelo do percurso histórico das tendências apresenta algumas etapas pelas quais vêm se dando, ao longo da história ocidental, os encontros e desencontros entre religião/teologia e literatura. As obras consultadas referem-se a quatro, cinco ou até seis etapas, dependendo do modo como as etapas são caracterizadas. A primeira etapa (ou uma das primeiras) representa um momento 
da história em que a dicção poética, em sua forma oral ou escrita, praticamente pertence ao âmbito da religião e do sagrado. Em seguida, numa dinâmica em que os dois campos já se apresentam de forma distinta, a literatura representará o lugar das perguntas, para as quais a teologia oferecerá respostas. Depois virá a etapa da divisão radical entre literatura e teologia: o rigor doutrinário não permitirá qualquer forma de diálogo com a liberdade da arte; da renascença ao século XIX, na Europa, os embates se caracterizarão, em geral, por uma crítica à religião e ao seu papel em relação à cultura. No século XX, ainda que o distanciamento e a desconfiança recíproca entre os dois campos continuem a se manifestar, a relação conflitiva vai cedendo espaço a uma correlação que tendeu para o dialogismo. Em invejável esforço para dialogar com a criação cultural, Rudolf Bultmann, Romano Guardini, Hans Urs von Balthasar, Paul Tillich e outros teólogos compreendem a literatura sob perspectiva teológica, destacam obras literárias como "literatura cristã", atribuem a obras literárias o caráter de "revelação". Mais recentemente, essa tendência de correlação radical entre teologia e literatura dá espaço a um modelo de diálogo criativo em que as obras literárias, na sua autonomia, adquirem relevância para a reflexão sobre o fato religioso. Há finalmente, hoje, uma tendência que anuncia o esgotamento e a impossibilidade do diálogo. Um panorama conciso desse percurso pode ser encontrado na introdução escrita por Paulo Astor Soethe para o livro Aragem do Sagrado (DE MORI; SANTOS; CALDAS, 2011, p. 11-23).

Também a ampla gama de autores de literatura encontrada na produção bibliográfica em Teopoética revela grande diversidade de interesses e, certamente, de possibilidades de construção de interfaces entre religião e literatura. A lista traz mais de trinta literatos. Seguindo a ordem estabelecida pela preferência dos pesquisadores, os autores/obras de literatura mais presentes na Teopoética são: a Bíblia, Guimarães Rosa, Adélia Prado, Clarice Lispector, Machado de Assis e José Saramago, lidos por seis ou mais pesquisadores. Em seguida, presentes nas publicações de pelo menos três pesquisadores, encontramos: Carlos Drummond de 
Andrade, Fernando Pessoa, Jorge de Lima, Jorge Luiz Borges e Friedrich Nietzsche. (Cf. gráfico 12, abaixo).

Gráfico 12: Autores mais lidos pelos pesquisadores em Teopoética

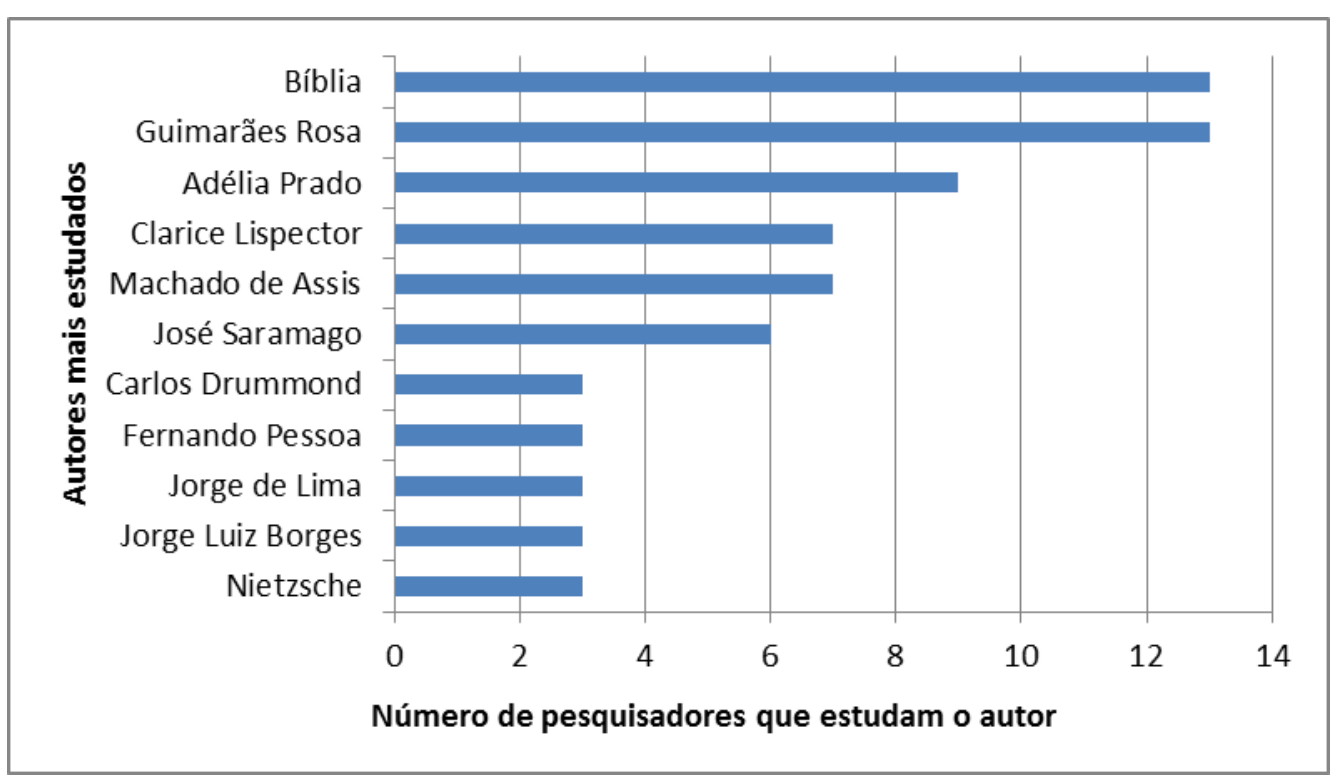

Fonte: Dados da pesquisa

Aparecem nas publicações de pelo menos dois pesquisadores: Cecília Meireles, Dostoiévski, Graciliano Ramos, Hilda Hilst, Mário de Andrade, Mia Couto e Dante. Aparecem pelo menos uma vez nas publicações em Teopoética: Agostinho de Hipona, Ariano Suassuna, Alceu de Amoroso Lima, Cruz e Souza, Eça de Queiroz, Euclides da Cunha, Gabriel Garcia Marques, Jorge Amado, Julien Green, Juan Rulfo, João Cabral de Melo Neto, Lars von Trier, Luís Fernando Veríssimo, Murilo Mendes, Manoel de Barros, Mário Quintana.

Em relação às obras mais lidas, destaca-se o Grande Sertão de Guimarães Rosa (aparece nas publicações de pelo menos 13 pesquisadores). O tema de maior interesse dos pesquisadores, em sua leitura de Grande Sertão, é a questão do confronto entre o bem e o mal. Em relação à Bíblia, cujo interesse iguala-se numericamente a Guimarães Rosa, os temas são variados: o êxodo, Sansão e Dalila, Jó, as narrativas dos evangelhos. 
Em relação aos temas tratados em Teopoética, sua variedade impede qualquer tentativa de quantificação sob algum critério taxonômico. Destaca-se, no entanto, o tema Satã e seus correlatos Lúcifer, Diabo, Demônio, Inferno, que aparecem nas publicações de pelo menos 16 pesquisadores.

\section{Avaliação e considerações finais}

Frente à diversidade de leituras de obras literárias em diálogo com o campo religioso e face à multiplicidade de justificativas para tal mister, qualquer esforço em busca de modelos interpretativos ou taxonômicos não logrará senão sucesso parcial. As perguntas voltam reiteradamente: Qual amostra de livros e artigos ler para chegar à delimitação de possíveis “modelos de leitura”? Na hipótese de adotarse o critério do percurso histórico para abordar o tema, certamente não teríamos material representativo senão da fase mais recente da Teopoética, aquela do diálogo estabelecido nas últimas três ou quatro décadas. Seria possível, na prática, identificar categorias interpretativas que permitissem construir uma taxonomia da produção em Teopoética no Brasil? Cada livro ou artigo seria "classificado" numa única categoria? E, no extremo, a quem poderia interessar o mapeamento do diálogo entre religião e literatura?

Julgamos que qualquer esforço em vista de delimitar modelos de leitura terá que considerar uma exigência fundamental: a de uma classificação "híbrida" da produção, onde uma mesma publicação poderá ser localizada em diferentes classes. Qualquer proposta de classificação da produção em Teopoética precisará levar em conta alguns pressupostos teóricos e metodológicos relacionados a uma concepção mais ou menos ampla de teologia, às interfaces entre religião e linguagem, à especificidade do mister literário, aos modos como a literatura se relaciona com a realidade histórica, às variadas possibilidades de diálogo entre religião e literatura. 
$\mathrm{Na}$ esteira de inúmeros teóricos, indicamos, à guisa de esboço, quatro possíveis "tipos” de produção em Teopoética:

a) o modelo da compreensão teológica da literatura, na esteira de Paul Tillich;

b) o modelo dialógico da literatura comparada, com foco no aspecto da intertextualidade;

c) o modelo dialógico teorizado, em que se busca a fundamentação teórica para as interfaces entre religião e literatura;

d) o modelo dialógico temático, em que se escolhe um tema do âmbito da religião para ser discutido pelo viés da crítica literária ou das ciências da religião.

Reiteramos que não há como classificar uma determinada publicação em Teopoética em apenas um desses tipos. Os modelos mostram-se imbricados. No máximo poderíamos falar da "tendência" de uma publicação situar-se neste ou naquele modelo. De qualquer modo, a tentativa de classificar a produção bibliográfica da área, ainda que por amostragem, demandaria leitura minuciosa do material - tarefa não empreendida por este trabalho.

\section{REFERÊNCIAS}

BARCELLOS, José Carlos; (GARCÍA, Flávio. Org.). Estudos literários reunidos: Compilação de 5 artigos de José Carlos Barcellos, já publicados esparsamente em periódicos. Rio de Janeiro: Ed. Dialogarts, 2008.

BARCELLOS, José Carlos. Literatura e teologia: perspectivas teórico-metodológicas no pensamento católico contemporâneo. Numen, Juiz de Fora, v. 3, n. 2, p. 9-30, 2000.

CANTARELA, Antonio Geraldo. $O$ caçador de ausências: o sagrado em Mia Couto. 2010. 185 fls. Tese (Doutorado) - Pontifícia Universidade Católica de Minas Gerais, Programa de Pós-graduação em Letras, Belo Horizonte.

CONCEIÇÃO, Douglas Rodrigues da. Literatura e religião em discussão: revisitando interpretações, métodos e teorias. Cadernos da FaEL, v. 3, p. 1-23, 2010. 
DE MORI, Geraldo Luiz; SANTOS, Luciano; CALDAS, Carlos. (Org.). Aragem do sagrado: Deus na literatura brasileira contemporânea. São Paulo: Loyola, 2011.

FERRAZ, Salma. As faces de Deus na obra de um ateu: José Saramago. 2.ed. Blumenau: Edifurb, 2012.

GROSS, Eduardo. Modelos hermenêuticos para a percepção do religioso na literatura. In: HUFF, Arnaldo Érico; RODRIGUES, Elsa. (Org.) Experiências e interpretações do sagrado. São Paulo: Paulinas, 2012. p. 99-115.

MAGAlHÃES, Antonio. Deus no espelho das palavras: teologia e literatura em diálogo. 2.ed. São Paulo: Paulinas, 2009.

MANZATTO, Antonio. Teologia e literatura: uma reflexão teológica a partir da antropologia contida nos romances de Jorge Amado. São Paulo: Loyola, 1994.

PAULA, Adna Candido de. Explicar e compreender: por uma teoria literária teológicareligiosa. In: SPERBER, Suzi Frankl. (Org.) Presença do sagrado na literatura: questões teóricas e de hermenêutica. Campinas: Publiel; Unicamp, 2011. p. 11-21.

ROCHA, Alessandro; YUNES, Eliana; CARVALHO, Gilda. (Org.) Teologias e literaturas: considerações metodológicas. São Paulo: Fonte Editorial, 2011.

SPERBER, Suzi Frankl. (Org.) Presença do sagrado na literatura: questões teóricas e de hermenêutica. Campinas: Publiel; Unicamp, 2011.

VILLAS BOAS, Alex. Teologia e Literatura como Teopatodiceia: em busca de um pensamento poético teológico. 2013. Tese (Doutorado) - Pontifícia Universidade Católica do Rio de Janeiro, Programa de Pós-graduação em Teologia, Rio de Janeiro. 